\title{
Daniel Berlyne and psychonomy: The beat of a different drum
}

\author{
JOHN J. FUREDY \\ University of Toronto, Ontario M5S 1A1, Canada \\ and \\ CHRISTINE P. FUREDY \\ York University, Downsview, Ontario M3J 1P3, Canada
}

\begin{abstract}
Daniel Berlyne's work influences many members of the Society: Yet in many respects, he was not a typical psychonome. We are researching a biography of Berlyne, and this paper presents some early working hypotheses for comment and criticisms of psychonomes who knew him or his work.
\end{abstract}

Daniel E. Berlyne (1924-1976) is recognized as one of the most creative experimental psychologists to work in Canada in the past 20 years. Berlyne's longest period of tenure at a university was the 14 years (1962-1976) that he spent at the University of Toronto, and during this period he probably contributed more than any other psychologist (D. O. Hebb's main contribution having been made somewhat earlier) to putting Canadian psychology "on the map." This contribution is evidenced not only by the frequency and variety of publications that have cited his work, but also by the theoretical contributions made by his motivational and later aesthetical research.

Berlyne's eminence is all the more interesting because his work was characterized by a maverick quality, not only in his independence of thought but also in his research methods and the way he taught research. Berlyne was different from his eminent peers in experimental psychology, and this difference increased over the years. It is this quality that gives further justification for a study of this scholar's career, for it throws into relief some dominant trends in experimental psychology. A study of Berlyne in the context of trends from which he diverged should produce insights not only into the scholar himself but into the discipline of psychonomy.

A few words about the term "psychonomy" seem in order, because it is some time since the term was coined, and its original meaning is not generally known. The term psychonomy was coined by a group of leading American experimental psychologists in the early 1960s who broke away from the American Psychological

This research was partly supported by an internal grant from the University of Toronto. A vital condition for this work, however, is the willigness of people to provide background information through interviews, and we wish, in particular, to acknowledge Hilde Berlyne and Roger Myers for providing material that allowed us to embark on this study.
Association in order to found a society that would be concerned with "pure" issues in experimental psychology rather than with applied or professional psychology. The term refers to the laws or principles (nomy) of psychology and was coined in order to indicate that "psychonomes" are concerned only with the principles of knowledge and not their application. From the beginning, however, the term was used in a confused way that Berlyne no doubt disapproved of. Specifically, experimental social psychology was tacitly excluded, presumably because of its cognitive approach. Thus, the principles of knowledge were, by implication, behavioristic ones. By now, of course, this behaviorist connotation has disappeared: Most psychonomes regard themselves as "cognitive" psychologists. However, the social psychologists are not generally thought of as psychonomes, as witnessed by the very small number of papers in the area offered at the annual convention, papers that are lumped together as covering "socialpersonality processes." 1 Thus, in current usage, the term psychonomy encompasses North American nonsocial experimental psychology.

In psychonomy so understood, we think that two important trends have become apparent in recent years. First, there has been an increase in the degree of specialization with a corresponding decrease in communication across areas that, to an outside observer, would seem to be closely related. This trend is illustrated by a glance at the Society's 1977 convention program, where, even within the "animal" field, the following sessions were scheduled as parallel (i.e., it was assumed that the psychonome would only want to hear one session and not the others): animal conditioning, avoidance animal learning, animal learning, and animal behavior.

Second (and we suspect that this trend is related to the first), psychonomes have been inclined to shift 
radically their basic theoretical positions as a function of changing scientific fashions or "paradigms." In particular, whereas most psychonomes of the 1950s were radical S-R behaviorists, now most (and often the same individuals) are "cognitive."

In contrast with the first trend of psychonomes toward increased specialization, Berlyne seems to have broadened rather than narrowed his range of interests during the last 2 decades of his life. This breadth of interest has been noted by commentators. For example, it has been recently written that "Berlyne belonged to the rare breed of psychologists who are equally comfortable with humans and rats as research subjects, equally knowledgeable about the work of Aristotle, Michelangelo, Freud, Pavlov, or Piaget, and equally familiar with the American and European (including-or perhaps, especially-Soviet) psychological literature" (Konecni, 1978, p. 136). Berlyne shared his readiness to do both human and animal research with Clark Hull, perhaps the most important precursor of psychonomy. Most modern psychonomes restrict themselves to one or the other area: Berlyne would have disagreed with the notion that these are two distinct "areas," if only because, like Hull, he believed that the principles (nomy) of psychology had to be examined as applying to both humans and animals.

Again, in contrast to the paradigm sensitivity of most psychonomes, Berlyne's theoretical approach was remarkably stable during the period when the paradigm changed over to cognitivism (Segal \& Lachman, 1972). His early work on nonbiological drives and curiosity was regarded by some S-R behaviorists as rather too mentalistic and cognitive, even though it was clear that his basic approach was a Hullian, S-R one. His last work in experimental aesthetics maintained this $S-R$ approach at a time when almost all the former Hullians had joined the "cognitive" camp, so to speak.

If a single term can be applied to summarize the quality of Berlyne's intellectual career, that term is "independence." From interview material we have collected as well as from other sources, it seems that Berlyne was extraordinarily interested in ideas for their own sakes. This was an aspect of his independence. To return to his Hullianism, he became a committed Hullian, but not as a result of personal contact with Hull, merely through reading Hull's Principles of Behavior. Yet he later rejected a basic tenet of Hull: that only biological drives were, in the end, important in behavior. Berlyne's individualism and independence were reflected in his teaching. Although in most cases the content of his students' postdoctoral work is related to problems that concerned Berlyne at the time, there is little similarity in form of thought and the experimental methods used by each student. In contrast, the form, though not always the content, of the work of former students of other eminent North American psychologists continues to show the influence of the supervisor under whom the student once worked.
The above claims about Berlyne and about the trends in psychonomy are put forward as tentative hypotheses to be tested against detailed evidence and arguments. We have put these claims forward here in order to elicit comments and criticisms from you on work that is at a very preliminary stage at this point. In the remainder of this paper, we would like to indicate what we regard as the potential significance of the work on which we have embarked.

Biographies of eminent scholars are useful not only because they contribute to understanding an outstanding mind but also because they illuminate the dynamics of academic creativity and success. Further, if the biography is explicitly contextual (i.e., sets the scholar in the context of the development of his discipline), it contributes to an understanding not only of the scholar but also the discipline he worked in and influenced. We think that examining the trends of specialization and breadth of scholarship, of paradigm conformity and independence, and other such characteristics through the career of one scholar will contribute to an understanding of the theoretical development of North American experimental psychology as a body of knowledge. While there have been studies of movements in psychology (e.g., Boring, 1953) as well as of shifting emphases (e.g., Segal \& Lachman, 1972), such analyses are written from the point of view of "insiders." This study will be one of a maverick or "outsider" and as such will provide a different perspective, contributing to the self-critical analysis that refreshes any discipline. We should make it clear that we do not intend to make judgments of whether Berlyne was right when he disagreed with other experts in his field. Rather, we hope to show what was common to such disagreements and thus to show the interactive relationship of an independent mind with the science that he influences but does not dominate.

More practically, many aspects of Berlyne's career will be of interest to university teachers, especially those concerned with teaching students to conduct research. Berlyne taught both his peers and his students how to do research, but his approach was significantly different from that adopted by most psychonomes. Once again Berlyne's "difference" will raise issues of the appropriate ways to structure teaching that aims to impart a grasp of the principles and methodology of scientific research.

For instance, will an educational system that favors a Berlyne-type scholar produce young researchers with greater independence and creativity in scientific investigation? Does the maverick scholar serve to shape critical and innovative minds among students? The question of whether independent (and strong-willed) minds produce other independent minds is obviously an open one: It may well be that students are so awed by the will of the eminent scholar that they follow his ideas slavishly. This study can do no more than suggest the type of influence that Berlyne had upon his 
students, but in doing so it will draw attention to an issue of considerable importance in higher education. It is for these reasons, then, that we seek your help (comments and criticisms) in our contextual biographical study of a psychonome who did seem to hear the beat of a different drum.

\section{REFERENCES}

Boring, E. G. A history of experimental psychology. New York: Appleton-Century-Crofts, 1950.

KoneCNi, V. Daniel E. Berlyne: 1924-1976. American Journal of Psychology, 1978, 91, 133-137.
SEgAL, E. M., \& LACHMAN, R. Is a scientific revolution taking place in psychology? American Psychologist, 1972, 27, 46-55.

\section{NOTE}

1. Additional evidence for the implicit exclusion of experimental social psychology from psychonomy is the fact that, a few years after the founding of the Psychonomic Society, a separate Society of Experimental Social Psychologists was formed. In those days, apparently, the feeling among many prominent psychonomes was that social psychological experiments were not "genuine," since they involved such "cognitive" manipulations as deception.

(Received for publication January 3, 1979.) 